\title{
Thrifty yes, genetic no
}

\author{
S. E. Ozanne, C. N. Hales
}

Department of Clinical Biochemistry, University of Cambridge, UK

Reaven, not for the first time, has provided a thoughtful and thought-provoking proposal placing insulin resistance in muscle as the central, genetically determined, factor in the aetiology of non-insulin-dependent diabetes mellitus (NIDDM). In his present synthesis he extends this proposal to embrace the evolutionary debate, largely triggered by Neel in 1962 [1], as to why such a, currently, deleterious genetic endowment should have survived natural selection over the previous several thousand years of human evolution. He concludes, as did Wendorf and Goldfine in 1991 [2], that muscle insulin resistance is the key feature that favoured the survival of primitive man, i.e. characterises the "thrifty genotype" proposed by Neel. Reaven, however, is now more mechanistically specific as to why insulin resistance in muscle would provide a survival advantage under primitive, early human living conditions. In doing this he draws upon earlier work from Cahill's laboratory emphasising the critical problem in human starvation of maintaining a nutrient supply to the brain and yet not degrading major amounts of body protein to produce the glucose which might be needed to achieve this. Cahill's studies showed that this problem was solved by the brain using $\beta$-hydroxybutyrate and acetoacetate as alternative fuels during starvation with a consequent reduction in the otherwise essential oxidation of glucose [3-5]. Reaven now suggests that in addition to this general basic mechanism, people with an NIDDM genotype, take up less glucose in muscle due to their insulin resistance, have consequently higher plasma insulin concentrations and this serves to conserve muscle protein (presumably due to insulin's known actions to enhance mus-

Corresponding author: Professor C.N.Hales, Department of Clinical Biochemistry, University of Cambridge, Level 4, Addenbrooke's Hospital, Cambridge CB2 2QR, UK cle amino acid uptake, increase protein synthesis and inhibit proteolysis - see below).

In reviewing this proposal we shall first consider what the evidence is that, by the single device of rendering muscle insulin resistant to its action on glucose disposal as seen in NIDDM, muscle protein conservation during starvation would result. Then we shall return to the thrifty genotype proposal to assess what is the current status of this hypothesis in the understanding of the pathophysiology of NIDDM.

It is well established that insulin acts to both stimulate protein synthesis and inhibit proteolysis in vitro [6]. However in vivo the primary effect of insulin on protein metabolism appears to be inhibition of proteolysis and the key target tissue appears to be skeletal muscle [7]. It may be expected that in insulin resistant states there may be increased proteolysis in muscle. However, consistent with Reaven's current proposal it has been reported that skeletal muscle proteolysis is reduced in NIDDM [8]. The molecular basis of the antiproteolytic action of insulin is not well understood. There is evidence that the insulin signalling pathway to inhibition of proteolysis and that to stimulation of glucose transport may differ. This is suggested by the observation that proteolysis in human skeletal muscle is more sensitive than glucose uptake to physiological increments in insulin [9]. In addition recent studies have suggested that phosphatidylinositol (PI) 3-kinase and p70 S6 kinase are both involved in the signalling of insulin's antiproteolytic action [10]. PI 3-kinase is also thought to play a key role in the regulation of glucose transport by insulin [11]. In contrast p70 S6 kinase is not thought to be necessary for stimulation of glucose transport by insulin [11]. This apparent divergence of insulin signalling pathways to glucose transport and proteolysis raises the possibility that they could be differentially regulated and that there may be selective resistance to insulin. This possibility is supported by the obser- 
vation that during short-term fasting muscle remains sensitive to insulin's antiproteolytic action despite the presence of a marked impairment in insulin mediated glucose disposal [12]. There are a number of examples where resistance to insulin is observed in one downstream pathway and not others. For example in pseudoacromegaly, which is associated with severe insulin resistance, resistance to the metabolic actions of insulin are observed [13]. However, patients remain sensitive to the mitogenic actions of insulin. An example of selective resistance to different metabolic actions of insulin can be seen in people with essential hypertension. A reduction in the ability of physiological insulin concentrations to stimulate whole body glucose uptake is observed. However a number of other actions of insulin (e.g. suppression of hepatic glucose output, lipolysis and lipid oxidation) are unaffected [14].

Reaven's proposal is dependent on NIDDM subjects being sensitive to insulin's anti-proteolytic action while being resistant to the stimulation of glucose disposal by insulin. In the absence of a more complete delineation of the respective pathways of insulin stimulation of glucose disposal and prevention of protein degradation it is difficult to propose, at the molecular level, mechanisms by which they may be differentially controlled. It is therefore equally difficult to test definitively whether such a differential control has a genetic basis. However if scientific theories or explanations survive by natural selection (which they surely do in a Popperian view of the advancement of scientific knowledge) then one must conclude that the thrifty genotype hypothesis of Neel is pretty "fit" in Darwinian terms. It therefore behoves those of us who would see it superseded to explain why it has survived so long and in turn to attempt to produce a replacement.

\section{"Fitness" features of the hypothesis are that it is:}

i) intellectually attractive in conceptually aligning survival of "diabetogenes" with the malaria-related survival of genetic abnormalities of human red cells [15]. This of course ignores the fact that the original hypothesis was misconceived by regarding all diabetes (insulin-dependent diabetes mellitus and NIDDM) as one condition. It was therefore considered by Neel to be potentially detrimental both during the conceptual and preconceptual stages of life which are vital for biological survival. We now recognise that NIDDM is largely post-reproductive and therefore natural selection may be partially or totally "blind" to its existence. Indeed Neel when he revisited the hypothesis in 1982 pointed out that there was "no really solid data on the reproductive handicap conferred by NIDDM in the modern management of mother and child" [16]. However, one must acknowledge many precedents for the thrifty geno- type hypothesis in (potentially) reaching the "right" answer for the "wrong" reason.

ii) genetic and we live in the age of the genetic triumphalism [17]

iii) too ill-defined to test. While Neel in 1982 proposed that the way to test the hypothesis was by prospective studies of children, such studies will not necessarily distinguish between the thrifty genotype versus for example the thrifty phenotype hypothesis [18]. In two separate studies in children we have shown changes in glucose metabolism to be linked to birth measurements which we interpret as being of environmental origin $[19,20]$. If the thrifty genotype hypothesis is not formulated in a manner which can be tested experimentally then disciples of Popper would say that it is not a hypothesis at all.

\section{Despite iii) how may it be criticised?}

i) The arguments supporting a genetic basis of NIDDM are weak [21].

ii) There is no precedent for a genetically determined disease affecting almost half of a number of disparate populations (American Indians, Pacific Islanders, Asian Indians).

iii) One of the puzzles of the epidemiology of NIDDM which has been largely ignored until very recently [22] is why "Westernisation" of many populations leads to an explosion of NIDDM and yet one of the most Westernised populations (Europeans) could be regarded as being abnormal in having low rates of NIDDM. The thrifty phenotype hypothesis actually predicts that improved nutrition over a number of generations, by improving fetal growth, will lead to this outcome. Indeed, we believe that this change is now emerging in Nauru [23]. This rapid change (in evolutionary terms) is contrary to what would be predicted by the thrifty genotype hypothesis.

iv) Despite great effort and much expenditure no genetic basis for NIDDM has emerged and recent pangenomic searches have been very disappointing.

v) An alternative hypothesis (thrifty phenotype) has emerged for which there is much circumstantial evidence and which is ultimately testable by intervention studies.

Having pointed out some of the contradictory features of these two hypotheses, it is equally important to recognise one key feature that they have in common, namely the proposal of an altered metabolic/endocrine setting which is favourable to survival under conditions of poor nutrition. Part of Reaven's hypothesis therefore is independent of how the nature/ nurture argument in NIDDM is resolved. Our understanding of the key metabolic/endocrine features which enhance survival under conditions of poor nutrition is still very limited. Is it poor appetite suppres- 
sion in a glut of nutrition, the ability to store and metabolise fat, ketoacidosis resistance, altered water and electrolyte handling, insulin resistance and reduced muscle proteolysis, as Reaven suggests or a combination of these and still other features? Reaven's hypothesis contains the essential feature of all useful hypotheses in that it suggests new and feasible experiments on the way to elucidating this important area of metabolism.

\section{References}

1. Neel JV (1962) Diabetes mellitus: "a thrifty" genotype rendered detrimental by "progress"? Am J Hum Genet 14: 353-362

2. Wendorf M, Goldfine ID (1991) Archaeology of NIDDM. Excavation of the "thrifty" genotype. Diabetes 40: 161-165

3. Cahill GF Jr, Herrera MG, Morgan AP et al. (1966) Hormone-fuel interrelationships during fasting. J Clin Invest 45: $1751-1769$

4. Owen OE, Morgan AP, Kemp HG, Sullivan JM, Herrera MG, Cahill GF Jr (1967) Brain metabolism during fasting. J Clin Invest 46: 1589-1597

5. Owen OE, Felig P, Morgan AP, Wahren J, Cahill GF Jr (1969) Liver and kidney metabolism during prolonged starvation. J Clin Invest 48: 574-583

6. Stirewalt WS, Low RB, Slaiby JM (1985) Insulin sensitivity responses of epitrochlearis and soleus muscles from fed and starved rats. Biochem J 227: 355-362

7. Denne SC, Liechty EA, Liu YM, Brechtel G, Baron A (1991) Proteolysis in skeletal muscle and whole body in response to euglycemic hyperinsulinemia in normal adults. Am J Physiol 261: E809-E814

8. Denne SC, Bretchel G, Johnson A, Liechty EA, Baron AD (1995) Skeletal muscle proteolysis is reduced in non-insulin-dependent diabetes mellitus and is unaltered by euglycaemic hyperinsulinaemia or intensive insulin therapy. J Clin Endocrinol Metab 80 (8): 2371-2377

9. Louard RJ, Fryburg DA, Gelfand RA, Barrett EJ (1992) Insulin sensitivity of protein and glucose metabolism in human forearm skeletal muscle. J Clin Invest 90 (6) 2348-2354
10. Dardevet D, Sornet C, Vary T, Grizard J (1996) Phosphatidyl 3-kinase and p70 S6 kinase participate in the regulation of protein turnover in skeletal muscle by insulin and insulin-like growth factor 1. Endocrinology 137 (10): 4087-4094

11. Fingar DC, Hausdorff SF, Blenis J, Birnbaum MJ (1993) Dissociation of p70 ribosomal protein S6 kinase from insulin-stimulated glucose transport in 3T3-L1 adipocytes. J Biol Chem 268: 3005-3008

12. Fryburg DA, Barrett EJ, Louard RJ, Gelfand RA (1990) Effect of starvation on human muscle protein metabolism and its response to insulin. Am J Physiol 259: E477-E482

13. Flier JS, Moller DE, Moses AC et al. (1993) Insulin mediated pseudoacromegaly: clinical and biochemical characterization of a syndrome of selective insulin resistance. $\mathrm{J}$ Clin Endocrinol Metab 76: 1533-1541

14. Ferrannini E, Haffner SM, Stern MP (1990) Essential hypertension: an insulin-resistant state. J Cardiovasc Pharmacol 15 [Suppl 5] S18-S25

15. Weatherall D (1992) The Harveian Oration. The role of nature and nurture. Royal College of Physicians, London

16. Neel JV (1982) The thrifty genotype revisited. In: J. Köberling and R. Tattersall (eds) The genetics of diabetes. Proceedings of the Serono Symposium, Academic Press, London and New York. 47: 283-293

17. Maddox J (1993) Has nature overwhelmed nurture? Nature 366: 107

18. Hales CN, Barker DJP (1992) Type 2 (non-insulin-dependent) diabetes mellitus: the thrifty phenotype hypothesis. Diabetologia 35: 595-601

19. Law CM, Gordon GS, Shiell AW, Barker DJP, Hales CN (1995) Thinness at birth and glucose tolerance in sevenyear-old children. Diabet Med 12: 24-29

20. Yajnik CS, Fall CHD, Vaidya U, et al. (1995) Fetal growth and glucose and insulin metabolism in four year old Indian children. Diabet Med 12: 330-336

21. Hales CN, Desai M, Ozanne SE (1997) The thrifty phenotype hypothesis: How does it look after 5 years? Diabet Med 14: 189-195

22. Swinburn BA (1996) The thrifty genotype hypothesis: how does it look after 30 years? Diabet Med 13: 695-699

23. Dowse GK, Zimmet PZ, Finch CF, Collins VR (1991) Decline in incidence of epidemic glucose intolerance in Nauruans: implications for the "thrifty genotype". Am J Epidemiol 133: 1093-1104 